University of Nebraska - Lincoln

DigitalCommons@University of Nebraska - Lincoln

Detection of insect fragments in wheat flour by near-infrared spectroscopy

\author{
J. Perez-Mendoza \\ USDA-ARS, perez@gmprc.ksu.edu \\ James E. Throne \\ USDA-ARS, Manhattan, KS, james.throne@ars.usda.gov \\ F. E. Dowell \\ USDA-ARS \\ J. E. Baker \\ USDA-ARS
}

Follow this and additional works at: https://digitalcommons.unl.edu/usdaarsfacpub

Perez-Mendoza, J.; Throne, James E.; Dowell, F. E.; and Baker, J. E., "Detection of insect fragments in wheat flour by near-infrared spectroscopy" (2003). Publications from USDA-ARS / UNL Faculty. 2062. https://digitalcommons.unl.edu/usdaarsfacpub/2062

This Article is brought to you for free and open access by the U.S. Department of Agriculture: Agricultural Research Service, Lincoln, Nebraska at DigitalCommons@University of Nebraska - Lincoln. It has been accepted for inclusion in Publications from USDA-ARS / UNL Faculty by an authorized administrator of DigitalCommons@University of Nebraska - Lincoln. 


\title{
Detection of insect fragments in wheat flour by near-infrared spectroscopy is
}

\author{
J. Perez-Mendoza*, J.E. Throne, F.E. Dowell, J.E. Baker \\ Grain Marketing and Production Research Center, USDA, ARS, 1515 College Avenue, \\ Manhattan, KS 66502, USA
}

Accepted 10 January 2002

\begin{abstract}
Insect fragments in commercial wheat flour are a major concern to the milling industry because consumers expect high quality and wholesome products at the retail level. Thus, the US Food and Drug Administration (FDA) has established a defect action level of 75 insect fragments per $50 \mathrm{~g}$ of flour. Millers routinely test their wheat flour to comply with this federal requirement and to deliver sound flour to their consumers. The current standard flotation method for detecting fragments in flour is expensive and labor intensive. Therefore, we examined the possible use of a rapid, near-infrared spectroscopy (NIRS) method for detecting insect fragments in wheat flour. We also compared the sensitivity and accuracy of the NIRS method with that of the current standard flotation method. Fragment counts with both techniques were significantly correlated with the actual number of fragments present in flour samples. However, the flotation method was more sensitive than the NIRS method with fragment counts below the FDA defect action level. We were unable to predict whether the number of fragments in a sample exceeded the FDA action level with our NIRS instrumentation. However, we were able to predict accurately whether flour samples contained less than or more than 130 fragments. Although current NIRS instruments are unable to detect insect fragments at the FDA action level, this method should be re-examined in the future because NIRS technology is rapidly improving. Published by Elsevier Science Ltd.
\end{abstract}

Keywords: Insect fragments; Flour; Action level; Detection; Near-infrared spectroscopy; Flotation method

\footnotetext{
${ }^{2}$ Mention of trade names or commercial products in this publication is solely for the purpose of providing specific information and does not imply recommendation or endorsement by the US Department of Agriculture.

*Corresponding author. Tel.: + 1-785-537-5570; fax: + 1-785-537-5584.

E-mail address: perez@gmprc.ksu.edu (J. Perez-Mendoza).
} 


\section{Introduction}

Primary pests of stored cereals, such as the rice weevil, Sitophilus oryzae (L.), and the lesser grain borer, Rhyzopertha dominica (F.), that develop and feed inside grain kernels are the main source of insect fragments in wheat flour (Campbell et al., 1976; Singh et al., 1976; Pedersen, 1992). The hidden immature stages and newly eclosed adults of the rice weevil, which remain inside the grain kernels for several days before emerging (Longstaff, 1981), are not easily detected or removed during normal cleaning or processing practices. A number of secondary pests that develop outside grain kernels can also contribute to insect fragments in cereal products. Therefore, care must be exercised during storage, handling, and processing of grain to minimize final product adulteration by insect fragments.

The Food and Drug Administration (FDA) administers the Federal Food, Drug and Cosmetic Act (FDCA) in the United States. It deals with, among other things, adulteration of foods and unsanitary conditions where foods are manufactured, packaged, and stored. Therefore, the FDA has set defect action levels for some unavoidable, naturally occurring food defects that are not hazardous to human health. In the case of insect fragments in wheat flour, the defect action level is 75 or more insect fragments per $50 \mathrm{~g}$ of flour (FDA, 1988). Several analytical methods for detecting insects and insect fragments in whole kernels and flour have been developed. Some of these methods use chloroform and carbon tetrachloride, exposing the analyst to possible contact with phosgene gas during drying (Glaze and Bryce, 1994). The current standard flotation method used by the FDA [972.32 light filth (pre- and post-milling) in flour (white), AOAC, 1997] is based on the principle that whole-wheat flour can be digested away without any effect on insect exoskeleton or mammalian hair contaminants. These oleophilic filth elements are separated from non-oleophilic food products by attraction to the oil phase of an oil-aqueous mixture. The oil phase is trapped off, filtered, collected on a filter paper, and examined microscopically to determine the amount and kinds of filth present (Glaze and Bryce, 1994). Recently, enzyme-linked immunosorbent assays (ELISA) techniques have been developed to measure insect contamination by detection of myosin (Quinn et al., 1992; Schatzki et al., 1993; Brader et al., 2002). These techniques eliminated the need for microscopic examinations. However, both the flotation method and the ELISA procedure are labor intensive and expensive. Therefore, development of a relatively simple, rapid, and accurate analytical method is highly desirable.

Near-infrared spectroscopy (NIRS) is a relatively fast, accurate, and economical technique available to the grain industry for compositional analysis. This technique can be used for both qualitative and quantitative analysis. NIRS has been used to identify several coleopteran species (Dowell et al., 1999), detect parasitized weevils in wheat kernels (Baker et al., 1999), and to detect external and internal insect infestation in wheat (Ridgway and Chambers, 1996; Ghaedian and Wehling, 1997; Dowell et al., 1998). The objective of this study was to determine whether NIRS has the potential to detect insect fragments in flour. As wheat flour becomes contaminated with fragments, slight changes that occur in its physical and chemical composition may influence NIR absorption characteristics. In this laboratory study, we compared the sensitivity of NIRS with that of the standard flotation method for determination of insect fragments in commercial wheat flour. 


\section{Material and methods}

\subsection{Preparation of insect fragments}

Rice weevils were obtained from cultures maintained on hard red winter wheat $(13.5 \%$ moisture content) at $27^{\circ} \mathrm{C}$ and $60 \%$ r.h. Adult weevils (3-4-week-old) from these cultures were removed by screening and frozen at $-20^{\circ} \mathrm{C}$ for $48 \mathrm{~h}$. Subsequently, weevils were held in a desiccator for $72 \mathrm{~h}$. The dry weevils were ground using a mortar and pestle, and screened through \#40 (0.425 mm) and \#60 $(0.250 \mathrm{~mm})$ sieves. We used fragments that passed through a \#40 sieve but were retained on a \#60 sieve. These fragments were similar in size $(\approx 0.4 \mathrm{~mm})$ to the insect fragments used by Glaze and Bryce (1994) during development of the AOAC 993.26 light filth in whole-wheat flourflotation method.

\subsection{Preparation of wheat flour samples}

Test samples were prepared by mixing $50 \mathrm{~g}$ of commercial wheat flour (Gold Medal All Purpose wheat flour, General Mills, Minneapolis, MN) with different numbers of insect fragments to produce the following concentrations: $0,35,75,150$, and 300 insect fragments per $50 \mathrm{~g}$ of flour. In order to obtain these concentrations, ten replicates of 35, 75, 150, and 300 fragments were counted manually and weighed on a Mettler UMT2 microbalance (USA Mettler Instrument Corporation, Hightstown, NJ). The average weight of each fragment concentration was used to prepare the test samples. A total of 300 samples (60 samples from each fragment level) were prepared for the development and validation of the NIRS calibration model.

\subsection{NIRS data collection}

A diode-array near-infrared spectrometer (DA7000, Perten Instruments, Springfield, IL) was used to collect absorbance $[\log (1 / R)$ where $R$ is diffuse reflectance] spectra from the test samples over a spectral range of $550-1700 \mathrm{~nm}$. Each sample was placed into a $13.3 \mathrm{~cm}$-diameter, $1.2 \mathrm{~cm}$ thick metal ring above a sample quartz window. The light beam came from below the quartz window and penetrated the sample. The diffuse reflectance was measured by an array of silicon and indium-gallium-arsenide sensors. Fifteen spectra were collected from each sample, averaged, and stored in a computer in $<1 \mathrm{~s}$.

A calibration model was developed by scanning 40 test samples of each insect fragment concentration $(N=200)$. The model was validated using another set of 100 samples by predicting the number of insect fragments present.

\subsection{Detection of insect fragments using the AOAC 972.32 flotation method}

This method was scaled down to detect insect fragments in $7.5 \mathrm{~g}$ samples of white flour. We digested $7.5 \mathrm{~g}$ of flour in a $250-\mathrm{ml}$ beaker with $90 \mathrm{ml} \mathrm{3 \%} \mathrm{HCl}$ solution by autoclaving for $5 \mathrm{~min}$ at $121^{\circ} \mathrm{C}$. The digested solution was sieved through a \# $100(0.150 \mathrm{~mm}$ openings $)$ sieve with tap water and transferred to a 1-1 beaker. Mineral oil $(7.5 \mathrm{ml})$ was added, and the resulting solution was stirred with heat on a magnetic hot plate for $5 \mathrm{~min}$. The mixture was transferred to a 2-1 
percolator/retaining beaker, filled with hot water, and allowed to stand with occasional stirring for $30 \mathrm{~min}$. The lower layer of the mixture was drained to almost $3 \mathrm{~cm}$ of the interface. This operation was repeated two to three times until the lower phase of the mixture was clear. After the final wash, the lower phase was drained, $3 \% \mathrm{HCl}$ solution was added to the top oil phase at almost $3 \%(\mathrm{v} / \mathrm{v})$, and the mixture was boiled on a magnetic hot plate for 3-4 min. It was then filtered through ruled filter paper into a filtration funnel with suction. Finally, the filter paper was transferred to a Petri dish and examined microscopically (AOAC, 1997). Insect fragments present in 20 samples of flour containing 0,3,7, and 11 insect fragments (five samples/fragment level) per $7.5 \mathrm{~g}$ of flour were analyzed by this method. The number of fragments recovered from the samples was compared with the predicted number of fragments obtained by the NIRS method.

\subsection{Statistical analysis}

Paired and multiple-comparison statistical analyses were performed on NIR spectra using partial least-squares (PLS) regression (Galactic Industries, 1996). In paired comparisons, all concentrations of insect fragments were paired and analyzed. Cross-validation was used to determine classification accuracy. Results were presented as the classification accuracy (\%) and the coefficient of determination $\left(r^{2}\right)$ when the optimum number of PLS factors was used. The number of factors selected was based on the reduction in residual sum of squares achieved by adding PLS factors to the calibration model. The PLS regression reports the importance of wavelengths used in calibrations as beta coefficients. For any given wavelength, the absolute value of the beta coefficient indicates how important that wavelength was for classification. Thus, beta coefficient plots can be compared to NIR absorption spectra of specific flour and insect fragment components such as protein, starch, insect lipids, or chitin to indicate which components cause unique NIR absorptions between flour samples with and without insect fragments (Dowell, 2000). An insect fragment prediction is obtained by multiplying the absorbance at each wavelength by the corresponding beta coefficient, and then summing each of those products across all wavelengths. Thus, the beta coefficients represent the calibration model. The value of the beta coefficients will change as the number of factors change, but the number of beta coefficients will not change.

The relationship between the number of fragments present in flour and the number of fragments recovered with the flotation method was determined by linear regression analysis (SAS Institute, 1991).

\section{Results and discussion}

\subsection{Detection of insect fragments by NIRS}

Results obtained when correlating absorbance to number of insect fragments in wheat flour showed that little classification information resulted from absorbance in the visible or very nearinfrared $(550-700 \mathrm{~nm})$ region. Including wavelengths below $700 \mathrm{~nm}$ probably does not improve classification accuracies because no significant visible differences existed between flour with and without low number of insect fragments. Based on the calibration studies, the wavelength range 
selected for final calibration to analyze the flour samples was from 700 to $1700 \mathrm{~nm}$ because this range provided the largest $r^{2}$ and the smallest standard error of prediction. The optimum number of PLS factors that resulted in the lowest classification errors ranged from 9 to 15 . The first few factors normally explain over $90 \%$ of the variance (Williams, 1996). Therefore, we selected 10 PLS factors for the final calibration because this model gave classification results similar to those achieved with a higher number of factors, and because less information is needed to explain variability in the data. This model was also more accurate in predicting the number of fragments in the validation set of samples, and beta coefficients produced from this model were less noisy and easier to interpret.

NIR spectra obtained from flour samples correlated well with actual number of insect fragments present in the flour samples (Fig. 1). When the calibration model developed from these flour samples was used to predict the number of insect fragments in the validation test samples, at least $90 \%$ of the samples that contained 75,150 , and 300 fragments per $50 \mathrm{~g}$ of flour were correctly classified as having more than 75 insect fragments. However, classification accuracy of the samples that contained 0 or 35 fragments was only $20-40 \%$. The calibration model tended to overestimate the number of insect fragments in samples that contained fewer than 75 fragments. Therefore, the calibration model generated with this commercial flour and with fragments from rice weevils was not sufficiently accurate in predicting the number of fragments in flour samples below the FDA action level. Using 130 fragments as the action level, $83.3 \%$ of the samples that contained 0,35 , and 75 fragments were correctly classified as having $<130$ fragments, and $90 \%$ of the samples that contained 150 and 300 fragments were correctly classified as having more than 130 fragments.

The absorbance spectra (Fig. 2) show higher absorbance at all wavelengths for the wheat flour without fragments. However, significant overlap in individual spectra across all wavelengths indicates that absorbance at one specific wavelength could not be used to detect insect fragments in wheat flour. Important wavelengths bands indicated by the beta coefficients occurred around

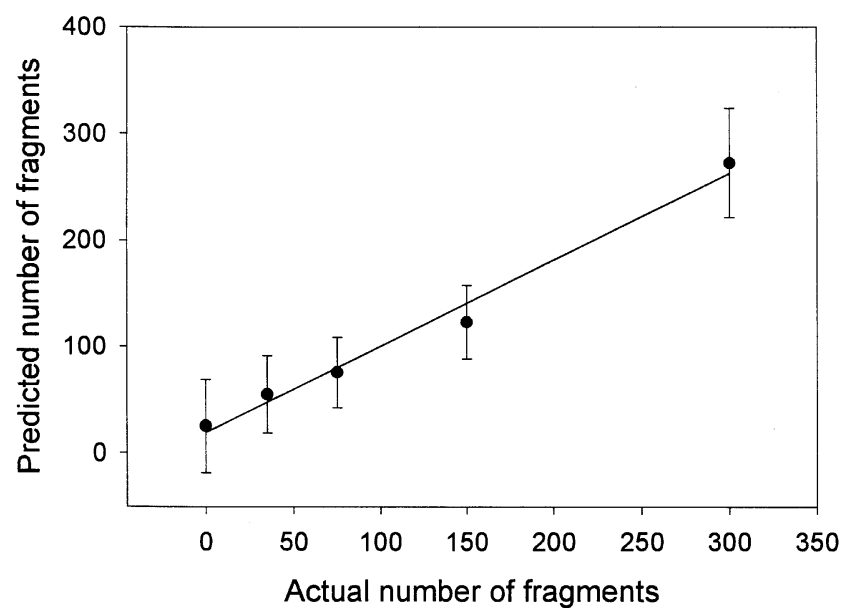

Fig. 1. Correlation of actual number of insect fragments $(x)$ to number of fragments predicted using NIR absorption spectra $(y)$ from wheat flour samples $\left(y=20.97+0.815 x ; R^{2}=0.80 ; N=200\right)$. Mean \pm SD of 40 replicates per fragment concentration in wheat flour. 


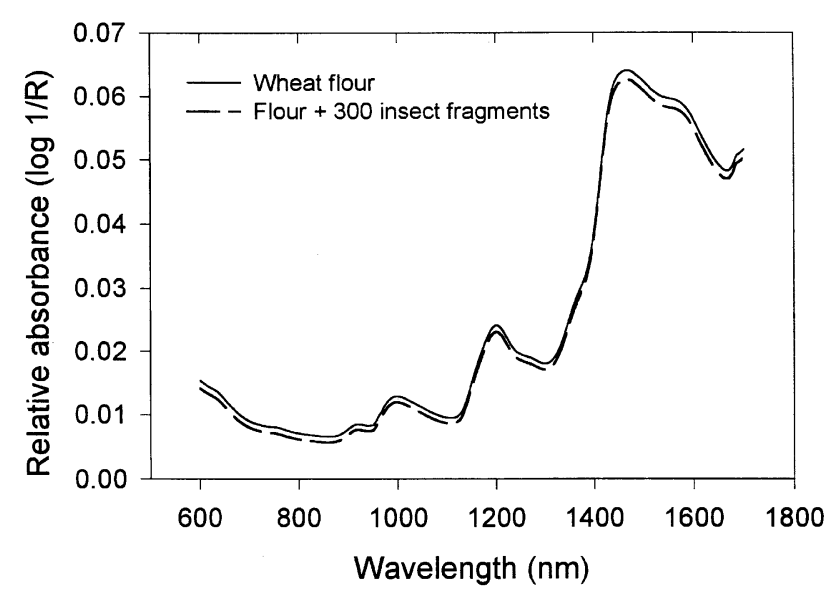

Fig. 2. Typical absorption spectra of flour with and without insect fragments.

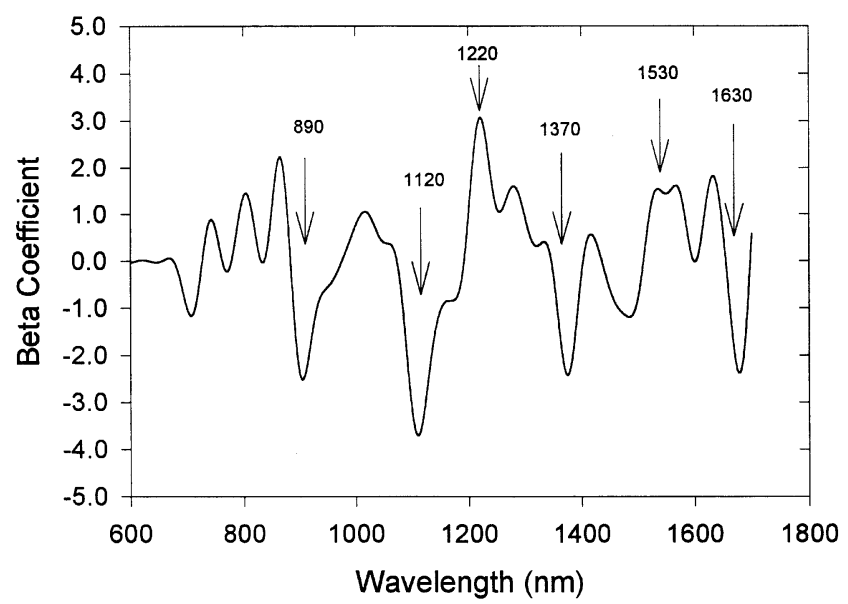

Fig. 3. Beta coefficients showing important wavelengths used by partial least-squares calibration to classify flour with and without insect fragments.

890, 1120, 1220, 1370, 1530, and $1630 \mathrm{~nm}$ (Fig. 3). These regions correspond to third, second, and first overtones of $\mathrm{CH}$ groups (Murray and Williams, 1990). These absorbance regions, in general, agree with those reported by Ghaedian and Wehling (1997) and Dowell et al. (1998) when detecting the presence of insects inside wheat kernels. Although these latter researchers used NIRS to detect hidden insects inside grain kernels, it is not surprising to find that the absorbance regions they reported agree with our data, because the same cereal and insect species were used in each study.

Absorption differences in the flour may be due to the presence of insect cuticle in the test samples. Cuticle contains both chitin and lipid, and several researchers have previously reported the influence of these components on the $\mathrm{C}-\mathrm{H}$ absorption region (Ridgway and Chambers, 1996; Ghaedian and Wehling, 1997; Dowell et al., 1998, 1999). Spectra of $\beta(1-4)$-linked hexasaccharide 
and of a 2-acetamido-2-deoxy-D-glucopyranoside derived from crab chitin showed absorbance peaks at $\approx 1178$ and $1500 \mathrm{~nm}$ (Dowell et al., 1998). Both of these wavelength bands were important in classification models in our study.

Cuticular lipids of insects are composed of hydrocarbons, esters, ketones, epoxides, alcohols, fatty acids, sterols, and triacylglycerols (Jackson et al., 1974; Blomquist and Dillwith, 1985). Insect cuticular lipids of the rice weevil constitute about $0.08 \%$ of the fresh weight of the weevil, and contain $n$-alkanes and $n$-alkadienes (Baker et al., 1984). $\mathrm{CH}_{3}$ and $\mathrm{CH}_{2}$ groups are common chemical constituents of most lipid classes, particularly the long-chain hydrocarbons. Spectra of cuticular lipids of the rice weevil showed absorbance peaks around 1130 and $1670 \mathrm{~nm}$ (Dowell et al., 1999); these peaks correspond to $\mathrm{CH}_{3}$ first and second overtones. Both wavelength regions were important in our classification model (Fig. 3). Thus, it is possible that the NIRS system may be detecting minor differences in lipid composition among the test samples.

\subsection{Detection of insect fragments using the AOAC 972.32 flotation method}

The number of insect fragments added to flour samples correlated highly with the number of insect fragments recovered from these samples using the standard flotation method $\left(R^{2}=0.98\right)$. The mean percentage recovery for all fragment levels was $93.6 \%$, this being similar to the mean percentage recovery reported by Glaze and Bryce (1994). The average time required for analysis of an individual sample using the flotation method was about $2 \mathrm{~h}$.

\subsection{Comparison of NIRS and the standard flotation method for detecting insect fragments in flour}

Although the flotation method is very sensitive at the FDA action level, this technique is time consuming (around $2 \mathrm{~h} / \mathrm{sample}$ ) and expensive. In contrast, although NIRS currently lacks the sensitivity of the flotation method, it is rapid $(<1 \mathrm{~min} / \mathrm{sample})$, does not require sample preparation and could easily be automated for a more sophisticated sampling protocol for large flour bulks. Moreover, ongoing advances in the capabilities and sensitivities of both mid-IR and NIR spectrophotometers may allow insect fragment detection at or below the defect action level, and this method should be re-examined in the future as the technology advances.

\section{Acknowledgements}

We thank Ann Redmon for excellent technical assistance. We also thank Thomas Phillips of the Department of Entomology, Oklahoma State University, and Bh. Subramanyam of the Department of Grain Science and Industries, Kansas State University for their valuable comments and suggestions on an earlier version of the manuscript.

\section{References}

AOAC (Association of Official Analytical Chemists), 1997. Official Methods of Analysis, pp. 16-17 (Chapter 16). Baker, J.E., Woo, S.M., Nelson, D.R., Fatland, C.L., 1984. Olefins as major components of epicuticular lipids of three Sitophilus weevils. Comparative Biochemistry and Physiology 77B, 877-884. 
Baker, J.E., Dowell, F.E., Throne, J.E., 1999. Detection of parasitized rice weevils in wheat kernels with near-infrared spectroscopy. Biological Control 16, 88-90.

Blomquist, G.J., Dillwith, J.W., 1985. Cuticular lipids. In: Kerkut, G.A., Gilbert, L.I. (Eds.), Comprehensive Insect Physiology, Biochemistry, and Pharmacology, Vol. III. Pergamon Press, New York, pp. 117-154.

Brader, B., Lee, R.C., Plarre, R., Burkholder, W., Kitto, G.B., Kao, C., Polston, L., Dorneanu, E., Szabo, I., Mead, B., Rouse, B., Sullins, D., Denning, R., 2002. A comparison of screening methods for insect contamination in wheat. Journal of Stored Products Research 38, 75-86.

Campbell, A., Singh, N.B., Sinha, R.N., 1976. Bioenergetics of the granary weevil, Sitophilus granarius (L.) (Coleoptera: Curculionidae). Canadian Journal of Zoology 54, 786-798.

Dowell, F.E., 2000. Differentiating vitreous and nonvitreous durum wheat kernels by using near-infrared spectroscopy. Cereal Chemistry 77, 155-158.

Dowell, F.E., Throne, J.E., Baker, J.E., 1998. Automated nondestructive detection of internal insect infestation of wheat kernels by using near-infrared reflectance spectroscopy. Journal of Economic Entomology 91, 899-904.

Dowell, F.E., Throne, J.E., Wang, D., Baker, J.E., 1999. Identifying stored-grain insects using near-infrared spectroscopy. Journal of Economic Entomology 92, 165-169.

FDA (Food and Drug Administration), 1988. Wheat flour adulterated with insect fragments and rodent hairs. Compliance Policy Guides. Processed Grain Guide 7104.511 (Chapter 4).

Galactic Industries, 1996. Grams/32 User's Guide, Version 4.0. Galactic, Salem, NH.

Ghaedian, A.R., Wehling, R.L., 1997. Discrimination of sound and granary-weevil-larva-infested wheat kernels by near-infrared diffuse reflectance spectroscopy. Journal of AOAC International 80, 997-1005.

Glaze, L.E., Bryce, J.R., 1994. Extraction of light filth from whole-wheat flour, flotation method: collaborative study. Journal of AOAC International 77, 1150-1152.

Jackson, L.L., Armold, M.T., Regnier, F.E., 1974. Cuticular lipids of adult fleshflies, Sarcophaga bullata. Insect Biochemistry, 4, 369-379.

Longstaff, B.C., 1981. Biology of the grain pest species of the genus Sitophilus (Coleoptera: Curculionidae): a critical review. Protection Ecology 2, 83-130.

Murray, I., Williams, P.C., 1990. Chemical principles of near-infrared technology. In: Williams, P.C., Norris, K.H. (Eds.), Near-Infrared Technology in the Agricultural and Food Industries. American Association of Cereal Chemists, St. Paul, MN, pp. 17-34.

Pedersen, J.R., 1992. Insects: identification, damage, and detection. In: Sauer, D.B. (Ed.), Storage of Cereal Grains and Their Products. American Association of Cereal Chemists, St. Paul, MN, pp. 435-489.

Quinn, F.A., Burkholder, W., Kitto, G.B., 1992. Immunological technique for measuring insect contamination of grain. Journal of Economic Entomology 85, 1463-1470.

Ridgway, C., Chambers, J., 1996. Detection of external and internal insect infestation in wheat by near-infrared reflectance spectroscopy. Journal of the Science of Food and Agriculture 71, 251-264.

SAS Institute, 1991. SAS System for Linear Models, 3rd Ed. SAS Institute, Cary, NC.

Schatzki, T.F., Wilson, E.K., Kitto, G.B., Behrens, P., Heller, I., 1993. Determination of hidden Sitophilus granarius (Coleoptera: Curculionidae) in wheat by myosin ELISA. Journal of Economic Entomology 86, 1584-1589.

Singh, N.B., Campbell, A., Sinha, R.N., 1976. An energy budget of Sitophilus oryzae (L.) (Coleoptera: Curculionidae). Annals of the Entomological Society of America 69, 503-512.

Williams, P., 1996. Observations on the use, in prediction of functionality in cereals, of weights derived during development of partial least-squares regression. Journal of Near Infrared Spectroscopy 4, 175-187. 